\title{
Revealing the Unexpected Two Variant Pairing Shifts Due to Temperature Change in a Single Bainitic Medium Carbon Steel
}

\author{
ADAM STÅHLKRANTZ, PETER HEDSTRÖM, NIKLAS SARIUS, \\ and ANNIKA BORGENSTAM
}

\begin{abstract}
The microstructure of a low alloy medium carbon bainitic steel, austempered in the temperature range $275{ }^{\circ} \mathrm{C}$ to $450{ }^{\circ} \mathrm{C}$ has been investigated by detailed electron backscatter diffraction and variant pairing analysis. It is observed that the variant pairing tendency has two distinct changes with varying temperature. At low temperature V1-V6 is the most frequent, whereas V1-V2 is the most frequent at intermediate temperature and at the highest temperature, V1-V4 dominates. This is distinct from the literature on low carbon steel where only two dominant variants pairs, related to the common distinction of bainite into lower and upper bainite, are typically reported. The change of the variant pairing in bainite also has many similarities with the change of variant pairing in martensite when its carbon content changes. Another observation is that the morphological orientation of cementite in the bainite has a strong relation with the variant pairing at lower austempering temperatures.
\end{abstract}

https://doi.org/10.1007/s11661-021-06408-0

(C) The Author(s) 2021

\section{INTRODUCTION}

BAINITIC steels are used in applications with high requirements on the mechanical properties, hence, detailed knowledge regarding the microstructure of bainite is a key aspect in order to optimize the mechanical properties for different applications.

The first stage of the bainitic transformation is the formation of acicular ferrite and whether this occurs through a diffusional ${ }^{[1-6]}$ or diffusionless ${ }^{[7-12]}$ transformation has been debated for a very long time. It is often referred to as "the bainite controversy". According to the diffusionless hypothesis bainitic ferrite is formed through diffusional nucleation and diffusionless growth. The bainitic ferrite formed will thus, according to this hypothesis, be supersaturated with carbon from which carbides can form within the ferrite or if the formation of carbides is prevented by e.g., a Si addition, the carbon will diffuse into the residual austenite ${ }^{[7,8,11]}$ On the other hand, according to the diffusional hypothesis the first stage of the bainitic transformation occurs through the

ADAM STAHHKRANTZ is with the Department of Material Science and Engineering, KTH Royal Institute of Technology, 11428 Stockholm, Sweden. Contact e-mail: Adamsta@kth.se PETER HEDSTRÖM and ANNIKA BORGENSTAM are with the Department of Material Science and Engineering, KTH Royal Institute of Technology. NIKLAS SARIUS is with the Husqvarna Group, 56182 Huskvarna, Sweden.

Manuscript submitted May 4, 2021; accepted July 16, 2021.

Article published online August 7, 2021 formation of thin bainitic ferrite plates that grow parallel to each other, constituting a packet, ${ }^{[13-15]}$ while the second stage can be regarded as an eutectoid transformation, which can be either cooperative or degenerate in its nature as discussed by Hillert, ${ }^{[1,16]}$ Aronson ${ }^{[17]}$ and more recently by Yin et al..$^{[13]}$ The cooperative eutectoid growth is characterized by ferrite and cementite growing together forming a lamellar structure if the carbon content is high enough. They grow preferentially at an angle to the primary ferritic plate and, moreover, both ferrite and cementite are in contact with the parent austenite during growth. ${ }^{[2]}$ The degenerate eutectoid growth, on the other hand, results in cementite in-between the ferritic plates with the same growth direction as the ferrite. ${ }^{[18]}$ Degenerate growth of bainite is more common at higher temperatures and the cooperative growth becomes more dominant towards lower temperatures.

Bainite is generally divided into upper and lower bainite relating to the temperature it is formed at. The terms originate from Mehl ${ }^{[19]}$ who observed two different morphologies of bainite, feathery and acicular. Over the years the ways to distinguish between the two has varied depending on whether it is based on the ferrite or carbide morphology and several definitions have been proposed. ${ }^{[20-23]}$ The different definitions were recently reviewed by Furuhara. ${ }^{[24]}$ It has been known since long that the transition temperature between different types of bainite varies with the carbon content of the steel and also that there is no sharp transition related to the 
morphology. This was observed already by Pickering ${ }^{[25]}$ and has been discussed recently by Yin et al. in relation to cooperative and degenerate eutectoid growth. ${ }^{[15,18]}$. Ohmori et al. ${ }^{[20]}$ related upper and lower bainite to the ferrite morphology and could also observe gradual changes with temperature. The only definition indicating a sharp transition of the bainite morphology is the one by Mehl. Mehl's description is based on the nucleation sites and specifies that upper bainite is related to intergranular nucleation, whereas lower bainite is related to intragranular nucleation.

It has been shown that the orientation relationship between the bainitic ferrite and the parent austenite follows the well-known Kurdjumov-Sachs (K-S), Greninger-Troiano (G-T) or Nishiyama-Wassermann $(\mathrm{N}-\mathrm{W})$ orientation relationships (ORs). ${ }^{[26-31]}$ This is similar to martensite even though the bainitic transformation is considered distinct from the martensitic transformation. Nonetheless, proponents for both hypotheses of bainite formation agree that bainite is formed through a displacive mechanism like martensite. For bainite, $\mathrm{K}-\mathrm{S}$ is the most frequently reported OR and will be used as a reference also in this study. According to $\mathrm{K}-\mathrm{S}$ there are 24 different possible crystallographic relations between the ferrite and the austenite, each called a variant, whereof each normally corresponds to one packet in the bainitic structure. These variants can be grouped into four close-packed plane groups referred to as CP-groups, where the variants in each group share the same parallel plane. Within each CP-group, six different relations between ferrite and austenite are possible considering the combination of three close-packed directions in FCC and two parallel close-packed planes in BCC, thus resulting in six different variants within each $\mathrm{CP}$-group. Furthermore, the relation between neighboring variants is called variant pairing, and can be used to describe crystallographic aspects of the microstructure. ${ }^{[32]}$

From works performed on both martensite and bainite it may be concluded that the carbon content and the transformation temperature have significant effects on the variant pairing. ${ }^{[31-36]}$ However, experimental studies on the effect of austempering temperature on the bainitic microstructure have mainly been conducted at high temperatures, above $400{ }^{\circ} \mathrm{C}$, and/or on samples with a carbon content lower than $0.5 \mathrm{wt}$ pct. The choice of low carbon steel and high austempering temperatures in previous studies can, at least partially, be explained by the effect of carbon on the martensite start temperature, i.e., it is not possible to study the bainitic transformation at a low temperature in a low carbon steel without interference from the martensitic transformation. Hence, in the literature, studies on local crystallography, preferred variant pairing, and morphology over a wide temperature range in low alloy bainitic steels with higher carbon content is lacking. Therefore, we here perform such a study. The effect of temperature on the variant pairing for a low alloy medium carbon bainitic steel and its relation to the microstructural morphology as well as upper and lower bainite is investigated. The results are utilized to discuss the nature of the bainitic transformation regarding its diffusional/diffusionless and displacive character. The martensitic microstructure of the same alloy has also been included for comparison.

\section{EXPERIMENTAL}

The investigated material was received in soft annealed condition with the chemical composition given in Table I. Samples of dimension $1.1 \times 6 \times 6 \mathrm{~mm}^{3}$ were cut and subsequently austenitized in a tube-furnace at $880{ }^{\circ} \mathrm{C}$ for $20 \mathrm{~min}$ in a protective argon atmosphere. Directly after austenitization, austempering for one hour was conducted in a Bi-Sn metal bath at different temperatures from $275{ }^{\circ} \mathrm{C}$ to $450{ }^{\circ} \mathrm{C}$ to achieve a fully bainitic material followed by quenching in brine. Shorter durations of austempering were also applied in order to achieve samples partially transformed to bainite and fully martensitic samples were obtained by direct quenching in brine after austenitization. The martensite start temperature for the material has previously been determined with dilatometry to $259{ }^{\circ} \mathrm{C}^{[37]}$ The transformation time for the formation of bainite was also determined with dilatometry, and all samples were confirmed to be fully transformed after 1 hour of isothermal holding.

The microstructures were examined by light optical microscopy (LOM), scanning electron microscopy (SEM) and electron backscatter diffraction (EBSD). Prior to microstructural characterization by SEM backscatter electron (BSE) imaging and EBSD, samples were mechanically polished until final polishing with $0.02 \mu \mathrm{m}$ colloidal silica; whereas, for SEM secondary electron (SE) imaging and LOM, samples were etched with picric acid after the mechanical polishing. The SEM work was conducted in a field emission gun scanning electron microscope (FEG-SEM) JEOL JSM-7800F with a Bruker e-FLASH ${ }^{\mathrm{HD}}$ EBSD attachment. The SEM was operated at $12 \mathrm{kV}$ with a working distance (WD) of $7 \mathrm{~mm}$ for imaging, while for EBSD 12 $\mathrm{kV}, 20 \mathrm{~mm} \mathrm{WD}$ and step size $30-50 \mathrm{~nm}$ were used. The EBSD post-processing was conducted using the QUANTAX CrystAlign software and MTEX, version 5.2. [38,39]

The methodology developed by Nyyssönen et al..$^{[40-43]}$ was applied for the orientation relation analysis. The method was originally developed for orientation analysis of martensite but can be directly applied to the bainitic structure, since both microstructures have similar orientation relation between parent and product phases, i.e., the $\mathrm{K}-\mathrm{S}$ relation. ${ }^{[40]}$ The algorithm applied uses the variant pairing definitions from Refs. ${ }^{[32,44,45]}$ To illustrate the combinations of variant pairing it is usually related to variant V1 according to Table II. This relation can be extended to cover each of the four CP-groups, however, when presenting results, all $\mathrm{CP}$-groups are summarized as if they would have been in the first CP-group e.g., V1-V6 is thus equivalent to V7-V12 and V13-V18, etc. It can be noted that the most common relations between variants is usually within the same CP-group. ${ }^{[33,46]}$ However, variant pairs belonging to different $\mathrm{CP}$-groups are possible and can even be the most dominant variant pairing which is seen, for 
Table I. Material Composition in Mass Pct

\begin{tabular}{cccccccccccc}
\hline $\mathrm{C}$ & $\mathrm{Si}$ & $\mathrm{Mn}$ & $\mathrm{Cr}$ & $\mathrm{Ni}$ & $\mathrm{Nb}$ & $\mathrm{S}$ & $\mathrm{P}$ & $\mathrm{Al}$ & $\mathrm{Cu}$ & $\mathrm{Fe}$ \\
\hline 0.61 & 0.21 & 0.36 & 0.10 & 0.90 & $\max 0.05$ & 0.0007 & 0.0090 & 0.0040 & 0.01 & bal. \\
\hline
\end{tabular}

Table II. The Variant Pairing Within One CP-Group Related to V1 and How the Different Combinations are Categorized ${ }^{[47]}$

\begin{tabular}{lcc}
\hline $\begin{array}{l}\text { Categorized } \\
\text { Pair }\end{array}$ & as Variant & Different Combinations of Variant Pairs Within the \\
CP-Group & $\begin{array}{c}\text { Shape Strain in Variant } \\
\text { Combinations }^{[32]}\end{array}$ \\
\hline V1-V2 & V1-V2, V3-V4, V5-V6 & 0.186 \\
V1-V3 or V1-V5 & V1-V3, V3-V5, V5-V1, V2-V4,V4-V6, V6-V2 & 0.228 \\
V1-V4 & V1-V4, V2-V5, V3-V6 & 0.123 \\
V1-V6 & V1-V6, V3-V2, V5-V4 & 0.049 \\
\hline
\end{tabular}

The shape strains for pure Fe between different variant pairs are also included.$^{[32]}$

example, in high carbon martensite. ${ }^{[33]}$ In addition to the CP-groups, the variants may be grouped according to the Bain correspondence, i.e. three groups, referred to as Bain groups. ${ }^{[46]}$ Variants within the same Bain group have a relatively low misorientation towards each other. Bain groups are also given in Table III. To identify the variant boundaries, the fast multiscale clustering (FMC) method in MTEX was used. The FMC method made it possible to also distinguish the more diffuse variant boundaries at higher temperatures. The variant boundaries were imported into the graphical user interface developed by Nyyssönen to calculate the variant pairing.

\section{RESULTS}

\section{A. Temperature Dependence of Microstructure Formation and Variant Pairing}

Typical microstructures formed after austempering at three different temperatures, $300{ }^{\circ} \mathrm{C}, 350{ }^{\circ} \mathrm{C}$ and $375^{\circ} \mathrm{C}$ are shown in Figure 1. The samples are only partially transformed to clearly show the morphological differences. It is evident that both the morphology and coarseness of the bainite change with increasing austempering temperature. The effect of austempering temperature on the bainitic microstructure is also seen in the inverse pole figure (IPF) maps shown in Figure 2. At lower temperatures, Figure 2(a) through (c), the microstructure in the IPF images appears plate-like with well-defined and straight boundaries separating different variants, while at higher temperatures, Figures 2(g) and (h), the structure becomes coarser and the boundaries become more irregular and the plate-like structure disappears. It is also noted that for the microstructures from the lower austempering temperatures the prior austenite grain boundaries (PAGB) are readily distinguishable, but this is not the case for the higher austempering temperatures.

By analyzing the crystallographic orientations, the variant pairing can be calculated from pole figure data (Figure 2(b)), as presented in Figure 3 for different austempering temperatures. Figure 3(b), shows a standard stereographic projection with the $\mathrm{K}-\mathrm{S}$ variants and the Bain groups. For bainite formed at the lower temperatures, $275^{\circ} \mathrm{C}$ and $300{ }^{\circ} \mathrm{C}$, V1-V6 is the dominant variant pairing, Figures $3(\mathrm{c})$ and (d). For the bainite formed at $325^{\circ} \mathrm{C}, \mathrm{V} 1-\mathrm{V} 6$ variant pairing is still present but it is no longer as dominant as at the lower temperatures and V1-V2 has become more frequent, Figure 3(e). Increasing the formation temperature further to $350{ }^{\circ} \mathrm{C}$ leads to $\mathrm{V} 1-\mathrm{V} 2$ becoming the dominant variant pairing while V1-V6 continue to decrease, Figure 3(f). It can also be noted that V1-V4 is the second most dominant variant pairing at this temperature. Increasing the temperature even further to $375^{\circ} \mathrm{C}$ results in $\mathrm{V} 1-\mathrm{V} 4$ becoming the most dominant variant pairing, Figure 3(g). A further increase in temperature will promote V1-V4 even more and V1-V8 becomes the second most dominant variant pairing, Figure 3(h). It is thus found that there are two distinct shifts of the most dominant variant pairing with increasing temperature. It should also be noted that V1-V4 and V1-V8 are variant pairs with low misorientation boundaries, Table III.

In Figures 2(a) and 3(a), an IPF map and the variant pairing for the fully martensitic structure after quenching is shown. The martensite has a different variant pairing than bainite formed at $275^{\circ} \mathrm{C}$, which is just above the martensite start temperature, Ms, thus clearly separating the two microstructures. The V1-V2 variant pairing is dominant and some V1-V16 is observed, however, it is only slightly more frequent than the other variant pairs V7-V24, it is however notable that V1-V16 is more frequent in the martensitic sample as compared to the bainitic samples.

\section{B. Variant Pairing Related to the Morphology of the Bainitic Ferrite}

To better understand how the variant pairing can be related to the bainite morphology, detailed analyses were conducted on austempered samples interrupted before fully transformed as presented in Figure 4. The bainite can be distinguished from the martensite in the SEM images as it is more easily etched than martensite as shown in Figure 1. Further, the EBSD pattern quality for bainite is better than for martensite since it is less 
dislocation-rich compared to the untempered martensite which has a very high dislocation density. It should be noted that the SEM and EBSD micrographs compared in Figure $4 \mathrm{a}$ and $\mathrm{b}$ are not exactly of the same area since some polishing has been conducted in-between the analyses.

The microstructure after austempering at $300{ }^{\circ} \mathrm{C}$, Figure 4(a), shows a primary bainitic plate with secondary units growing with an angle to the primary plate. This is also shown in Figures 1(a) and (d). The variant analysis shows that the primary and secondary plates have a specific variant pairing, V1-V6, which is in good agreement with the most frequently observed variant pairing at this temperature, Figure 3(d). When the austempering temperature is increased to intermediate temperature, $350{ }^{\circ} \mathrm{C}$, bainitic plates form more in parallel with each other, as shown in Figures 1(b) and (e) and 4(b). The variant pairing of the parallel plates in Figure 4(b) is V1-V2, which also is the most frequent variant pairing at this austempering temperature, Figure 3(f). When the austempering temperature is increased even further, to $375{ }^{\circ} \mathrm{C}$, mainly V1 and V4 (equivalently V2-V5, Table II) is shown, but some V1-V2 can also be seen in the lower left corner in Figure 4(c). It is here also seen that the boundary between the two variants is rather diffuse resulting in the bulkier morphology with a gradual color change from V2 to V5. In Figure 4(c2) the misorientation angles across the gradual color change in the IPF image in Figure 4(c) are given. The gradual change is about the same as the experimentally determined misorientation angle between V1-V4 as shown in Table III.

At higher austempering temperatures PAGB are harder to distinguish, as already shown in Figure 2, and here further illustrated in Figure 5 where the same variants can be seen growing as chevrons ${ }^{[18]}$ on both sides of the PAGB indicated with a dotted white line in the IPF image. In a fully transformed structure this PAGB would have been difficult to identify using EBSD. It can be noted that the growth direction in the different grains is altered due to different crystallographic orientations of the parent austenite grains (PAG).

\section{Morphology of Cementite in Relation to Bainitic Ferrite Variant}

In addition to the bainitic ferrite, the cementite formed during austempering at 300,350 and $450{ }^{\circ} \mathrm{C}$ was also analyzed and the change in cementite morphology with temperature is shown in Figure 6. For the bainite formed at lower austempering temperatures, the cementite and ferrite seem to grow in a eutectoid cooperative manner with an angular deviation to the main growth direction of the leading ferritic plate in the same way as previously described in detail by Yin et $a l .{ }^{[13]}$ While in the bainite formed at the higher temperature, $450{ }^{\circ} \mathrm{C}$, the cementite seemingly forms in-between the ferritic plates and thus it is parallel to the main growth direction of the ferrite as a result of a more degenerate eutectoid growth as described by Yin et al. ${ }^{[13]}$
It can also be seen that the cementite coarsens with increased austempering temperature.

The variants observed in the bainitic ferrite hitherto discussed, were also found to have a relation with the morphology of the cementite formed during the bainitic transformation. This relation is primarily observed in bainite formed at the lower and intermediate temperatures where the transformation is observed to mainly take place cooperatively. The morphological relations are shown in Figure 7, where the cementite in the variant pairs corresponding to V1-V6 (equivalently V2-V3) is found to form at an angle towards each other, Figure 7(a). For the intermediate temperature, where $\mathrm{V} 1-\mathrm{V} 2$ is the most frequent variant pair, the cementite in the different variants is parallel as shown in Figure 7(b). In Figure 7a, it can also be observed that cementite within variants V1, V2 and V5, V6 are parallel.

The morphology of the cementite is an additional difference when comparing to the martensite. Cementite precipitating from the martensite grow in three different main directions within a single martensitic plate, as shown in Figure 8 for martensite tempered at $300{ }^{\circ} \mathrm{C}$. For bainite formed at $275^{\circ} \mathrm{C}$ the cementite is growing in a single direction together with the ferrite resulting in a lamellar structure as shown in Figure 9. It is also shown that both cementite and ferrite are in contact with the austenite during the thickening of the bainitic plate.

\section{DISCUSSION}

\section{A. Temperature Dependence of the Variant Pairing}

Changes in variant pairing of bainite with temperature have previously been reported ${ }^{[34,35,46,48]}$ but the observation of three different dominating variant pairing in the same alloy at different temperatures, as here observed, has not been reported previously. Kaneshita et al., ${ }^{[34]}$ investigated a low alloyed steel with $0.75 \mathrm{wt}$ pet carbon partly transformed to bainite at $400{ }^{\circ} \mathrm{C}$ and $500{ }^{\circ} \mathrm{C}$ and observed variant pairs with small misorientation such as V1-V4 and V1-V8 dominating at high temperature as also observed in this work. It should be noted that the grain size in their work was much larger and that they also observed variants that were nucleated inside the PAG. Takayama et al. ${ }^{[46]}$ investigated a low carbon steel with $0.15 \mathrm{wt}$ pct carbon, and concluded that variant pairs belonging to the same Bain group tend to form at higher temperatures, especially variant pairs with low misorientation angle as also observed in this study for the higher austempering temperatures. The studied austempering temperatures were higher than in this study due to the lower carbon content of their studied steel. They did not report any V1-V6 pairing and at the lowest temperature studied, $450{ }^{\circ} \mathrm{C}$, they observed V1-V2. The large difference in carbon content makes the comparison difficult, but they did report the same trend for variant pairing at intermediate and high temperatures as in the present study. Morito et al. ${ }^{[48]}$ determined the variant pairing of bainite at temperatures between 300 and $400{ }^{\circ} \mathrm{C}$. For the bainite formed at the lower temperature the most frequent variant pairing was 


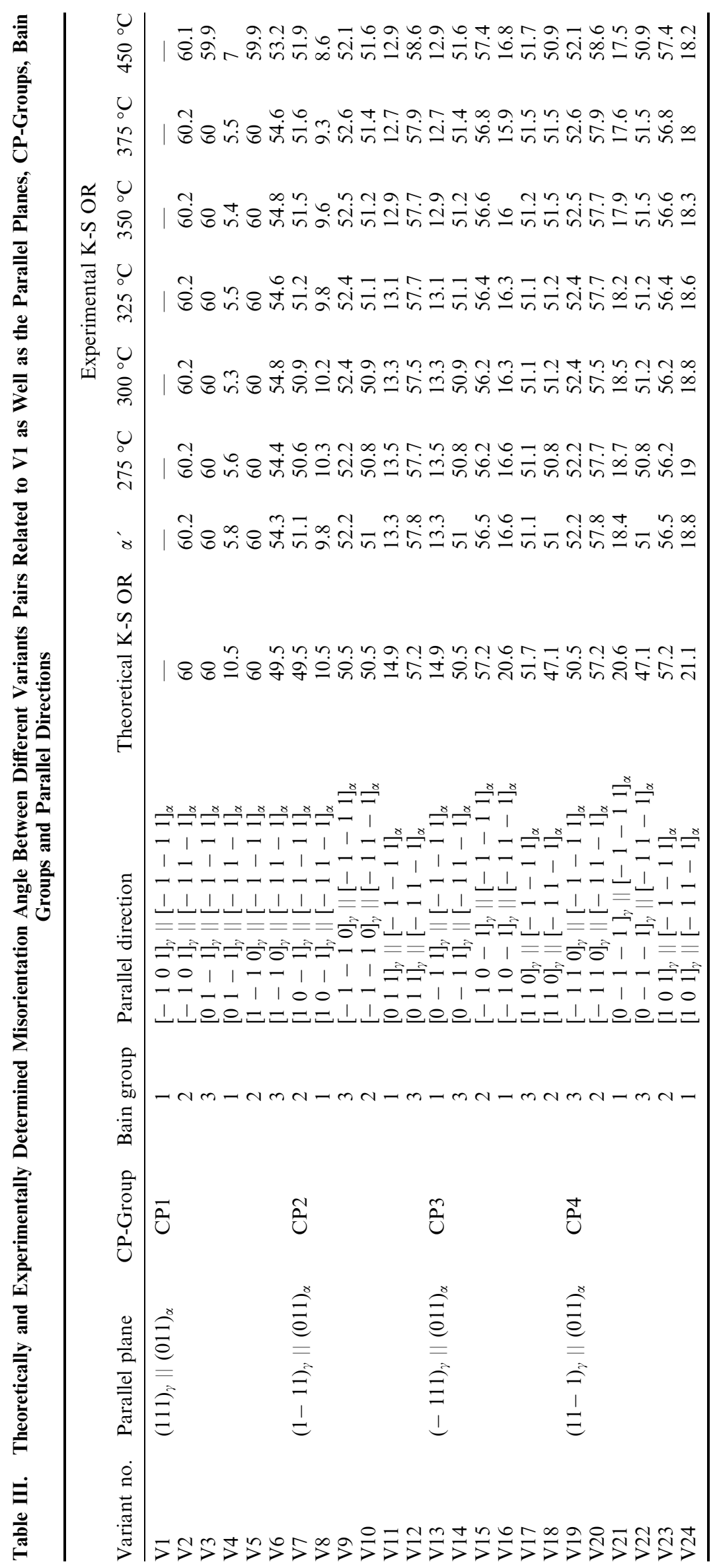



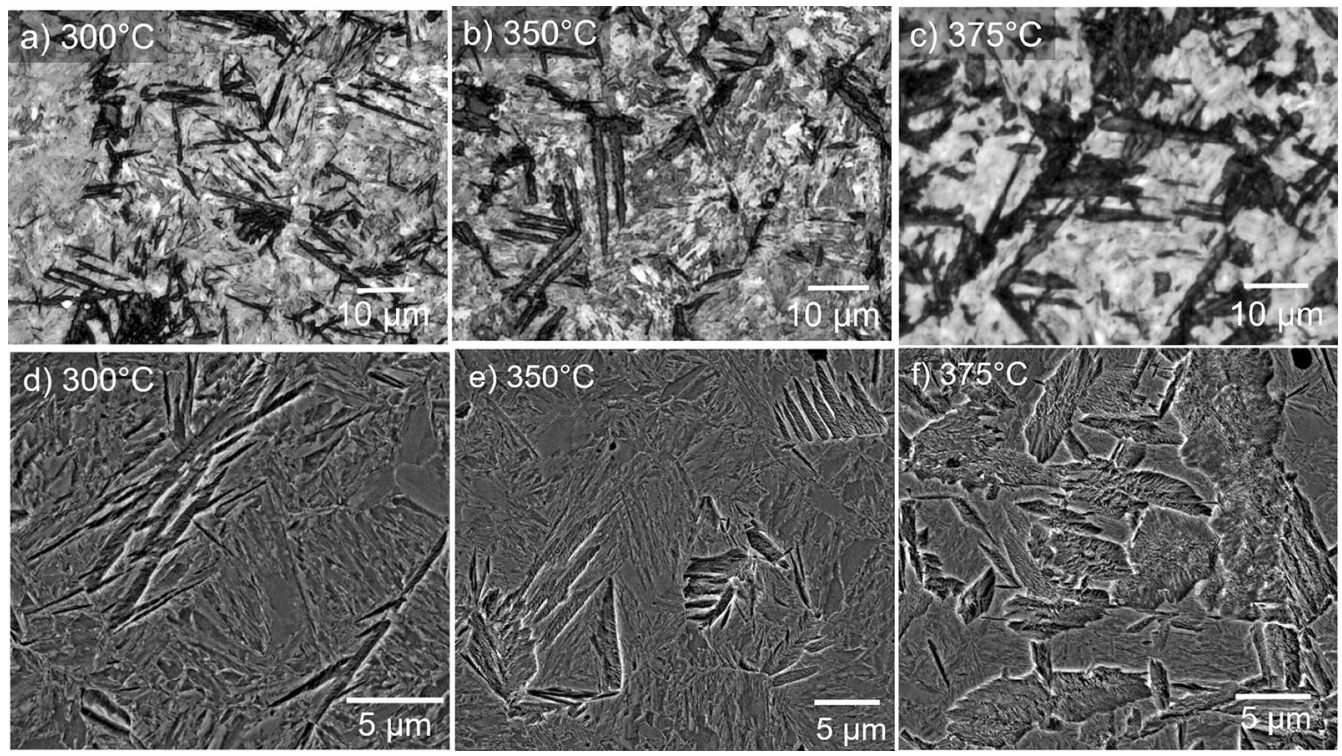

Fig. 1-Partly transformed microstructures observed with ( $a$ through $c$ ) LOM, where darker areas are bainite, and $(d$ through $f)$ SEM, where bainitic areas are more etched, held for (a, d) $120 \mathrm{~s}$ at $300{ }^{\circ} \mathrm{C}$, (b, e) $75 \mathrm{~s}$ at $350{ }^{\circ} \mathrm{C}$, and (c, f) $60 \mathrm{~s}$ at $375^{\circ} \mathrm{C}$.

V1-V6 in accordance with the results in this work. With increased temperature they showed that V1-V6 was replaced by V1-V2, also in accordance with this work. Furuhara et al. ${ }^{[35]}$ investigated the crystallography in an alloy containing $9 \mathrm{wt}$ pet $\mathrm{Ni}$ and $0.15-0.5 \mathrm{wt}$ pct carbon in the temperature range $350-450{ }^{\circ} \mathrm{C}$ and reported that V1-V2 occurred more frequently at the lower temperatures and V1-V4 at higher temperatures, also in accordance with the present results. So in conclusion, the three different dominating variant pairs observed in this study have been observed previously but not in the same alloy. It could be speculated that this transition of variant pairing holds in general but that it is not possible to observe in many alloys, since the temperature range where bainite can form without interference from other microconstituents is limited, i.e., martensite at lower temperatures and pearlite at higher temperatures.

It could be argued that the variant pairs observed at the higher temperatures are not of the same kind as the ones at lower temperatures, since there is no sharp boundary between the variants. It is rather a gradual shift as shown by the color scale in Figure 4(c). This can be explained by a change in misorientation in the range of 5-6 degrees as shown in Figure 4(c2) which is here identified as two different variants. These variant pairings also contain two variants within the same Bain group which differs from the other types of variant pairing which are made up of variants from different Bain groups. It can also be noted that if $\mathrm{N}-\mathrm{W}$ would have been used, which have 12 possible crystallographic orientations, variant pairs belonging to the same Bain group in the present work instead should have been considered as a single variant. The shift in misorientation within the ferrite plates in the same packet has previously been presented by Yin et al. ${ }^{[14]}$ where it was described as a rotation of the bainitic plate during widening. It is also noted that there is a deviation from the theoretical and experimental misorientation angles for V1-V4, V1-V8 and V1-V6, decreasing with increasing temperature, see Table III, as previously reported. ${ }^{[46,47]}$ It could thus be questioned if the gradual change in orientation should be regarded as a variant pair, but still it is evident that there are two distinct changes in local crystallography with temperature resulting in three apparently different dominant variant pairs at different temperatures.

\section{B. Morphology of Bainitic Ferrite Related to the Variant Pairing}

In the work previously mentioned by Morito et al..$^{[48]}$ they used variant pairing as a tool for structural determination of martensite, lower bainite and upper bainite. The bainite formed at the lower temperature was characterized as lower bainite where the most frequent variant pairing was V1-V6 and with increased temperature they characterized the bainitic structure as upper bainite when the most frequent variant pairing had shifted to V1-V2. They could thus relate lower and upper bainite to a certain variant pairing. In this work, bainite formed at the highest temperature investigated, $450{ }^{\circ} \mathrm{C}$, is mainly formed by a degenerate eutectoid as shown in Figure 6(b) and with decreasing temperature the tendency of cooperative growth increases as shown in Figure 6(a) from $300{ }^{\circ} \mathrm{C}$. These changes in morphology could be related to upper and lower bainite, even if it was recently argued that it is not a convenient way due to the lack of a sharp transition. ${ }^{[13]}$ Regardless, it can be concluded that the changes in variant pairing with temperature in the current steel cannot directly be related to upper and lower bainite, in contrast to the suggestion by Morito et al., since two distinct changes in variant pairing occur with increasing temperature. If the division into upper and lower bainite based on the cementite was to be used, V1-V6 and V1-V2 would in the current material both be characterized as lower 

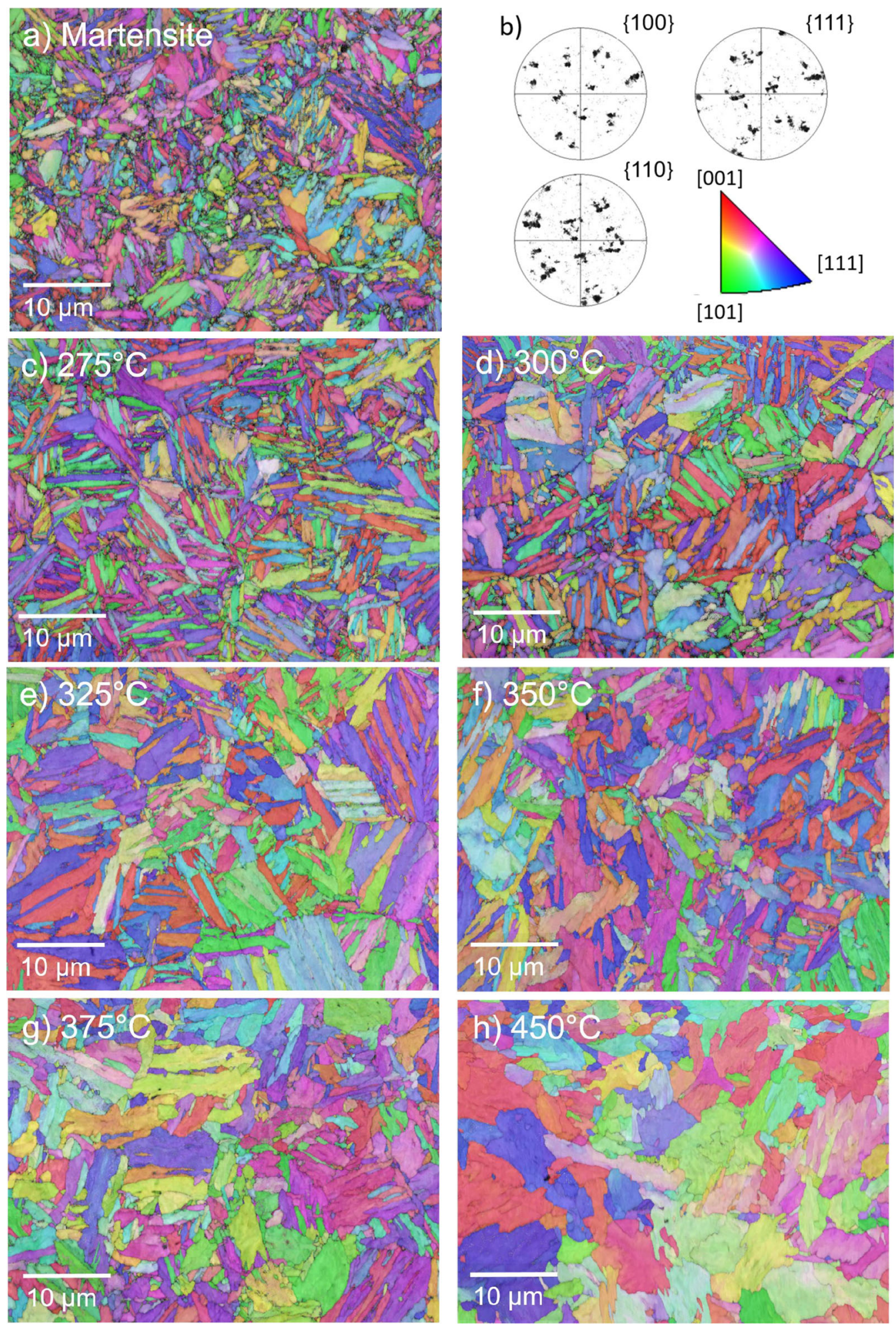

Fig. 2-(a) IPF map of martensite, (b) IPF color and pole figure of a single austenite grain taken at $275^{\circ} \mathrm{C},(c$ through $h)$ IPF maps of bainite with increasing austempering temperature.

bainite according to the fine lamellar structure of cementite and ferrite as a result of a cooperative eutectoid growth, Figure 9. The high temperature structure, Figure 6(b), has the more characteristic upper bainite structure with cementite in-between the ferrite plates as a result of degenerate eutectoid growth, and the dominant variant pairing at this temperature is V1-V4. However, it should be emphasized that Morito et al. only investigated two temperatures and did thus not observe the shift to V1-V4 as here observed at the higher 

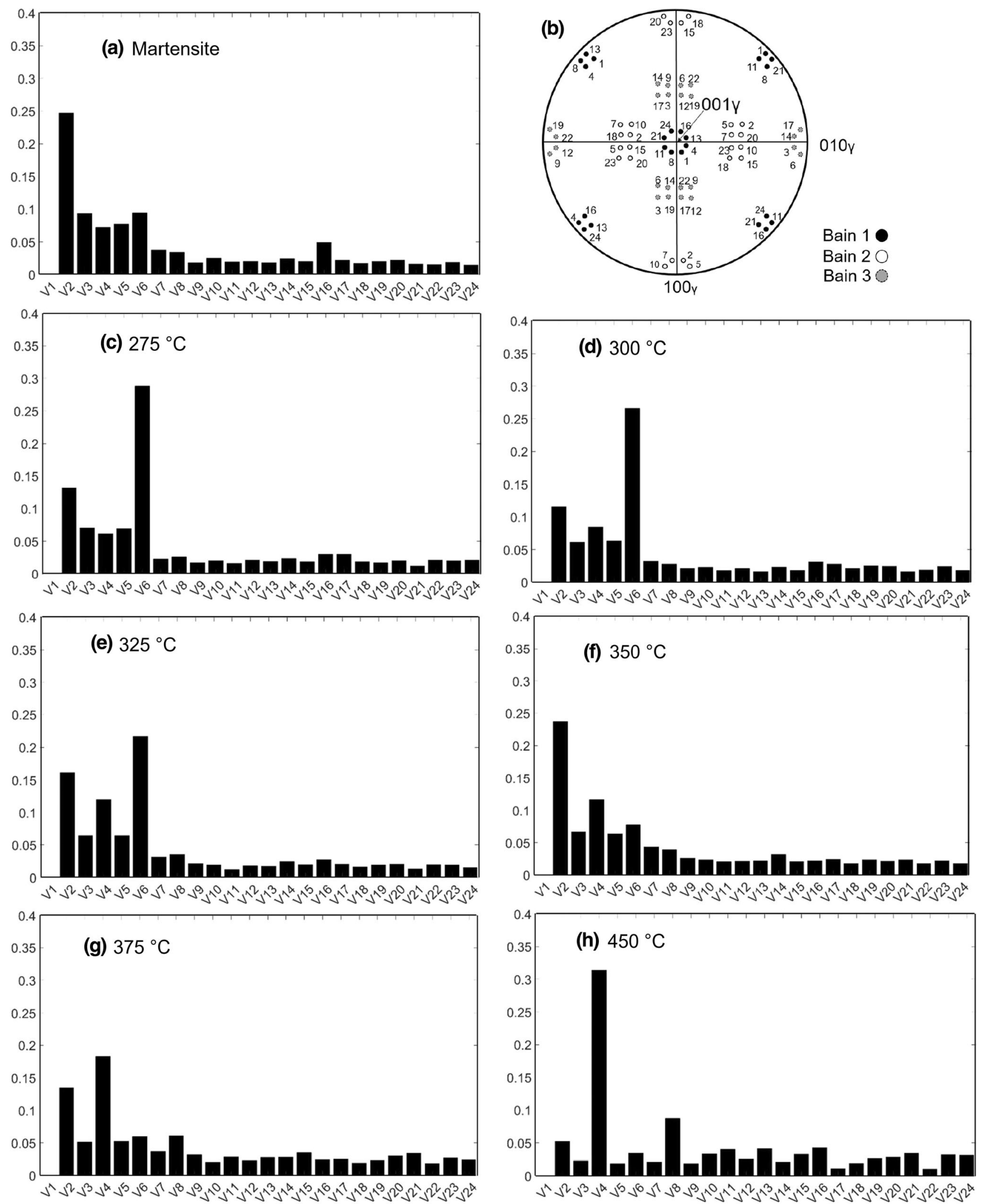

Fig. 3-The variant pairing related to V1 calculated using $\operatorname{MTEX,~}(a)$ for martensite, $(c$ through $h)$ for bainite formed with increasing austempering temperature. (b) Stereographic projection with K-S and Bain groups visualized. 


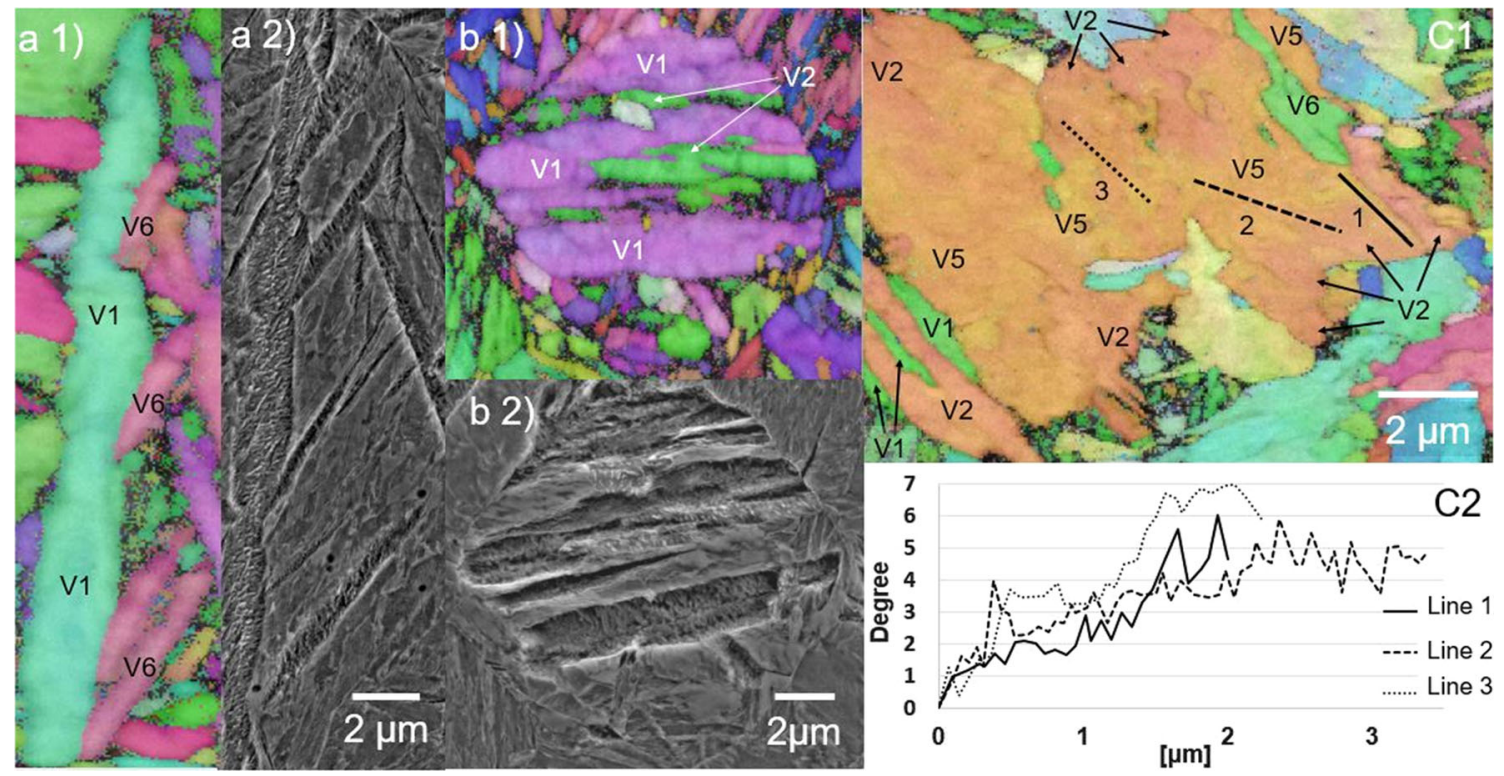

Fig. 4-SEM and corresponding EBSD area of partly transformed microstructures with the variant pairs indicated in the EBSD image after (a) $120 \mathrm{~s}$ at $300{ }^{\circ} \mathrm{C}$, (b) $75 \mathrm{~s}$ at $350^{\circ} \mathrm{C}$ and $(c) 60 \mathrm{~s}$ at $375^{\circ} \mathrm{C}$. In $(c)$ several line scans showing the misorientation angle have been included.

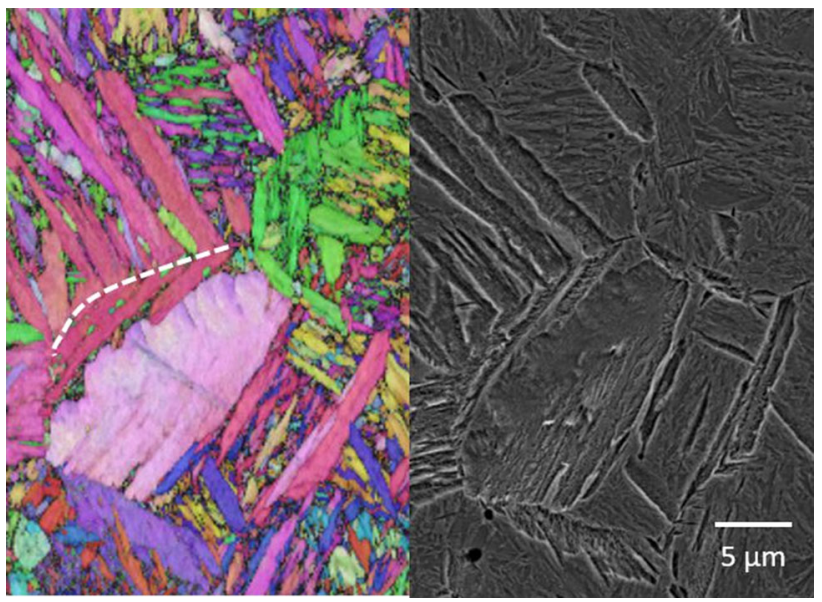

Fig. 5-IPF image of an interrupted sample after $75 \mathrm{~s}$ at $350{ }^{\circ} \mathrm{C}$. The dashed line indicates a PAG boundary, the same variant can be seen growing on both side of the PAG boundary resulting in a chevron packet at the dotted line.

temperatures. It should also be emphasized that no intragranular nucleation, which sometimes is used to separate upper and lower bainite, was observed in this work.

When comparing the partly transformed samples, Figure 4, with fully transformed samples, Figure 2, it is observed that the growth of the variant pairs seems to occur in a rather cooperative manner where both variants are growing simultaneously but in different ways depending on the temperatures. For bainite formed at lower temperature the different variants forms at an angle to each other, Figure 4(a), in agreement with other observations at similar temperatures ${ }^{[18,19,49]}$ while at intermediate and higher temperature they form more parallel to each other as shown in Figure 4(b).

\section{Comparison of Variant Pairing in Bainite and Martensite}

It is noted that there are similarities in variant pairing in bainite and martensite. As here shown, three different variant pairings are observed for bainite formed at different temperatures which can be compared with three different variants pairing for martensite with different carbon content, ${ }^{[33]}$ and thus formed at different temperatures since Ms decreases with increasing carbon content. For bainite formed at intermediate austempering temperature, and medium carbon martensite, $0.6-1.05$ wt pct, V1-V2 is the preferred variant pairing. ${ }^{[33,48]}$ For bainite formed at high austempering temperatures and for low carbon martensite, 0-0.35 wt pct, ${ }^{[3,46]}$ both have variant pairs with low angle boundaries, V1-V4. For bainite formed at the lowest austempering temperatures V1-V6 is the most frequent variant pairing while for high carbon martensite, $>1.05$ wt pct, the most frequent variant pairing is V1-V16. Despite this difference the similarities are striking. One could argue that even if martensite is diffusionless and bainite diffusional, a possible explanation to these similarities could be the fact that both are displacive. Previously several explanations have been proposed for the change in variant pairing in both bainite and martensite. ${ }^{[32,33,35,46,47]}$ Furuhara et al. ${ }^{[35]}$ proposed two explanations for the change in variant pairing in bainite, also comparing with martensite, which was further elaborated on by Takayama et al. ${ }^{[4]}$ One is the increased driving force with the decreasing temperature leading to a smaller difference in activation energy between nucleation of different variants, thus more variants can be formed in a certain PAGB. The other is the strengthening effect of the austenitic matrix with decreasing temperature which would lead to a change in variant selection in order to accommodate transformation strains of the bainitic transformation better as it is 

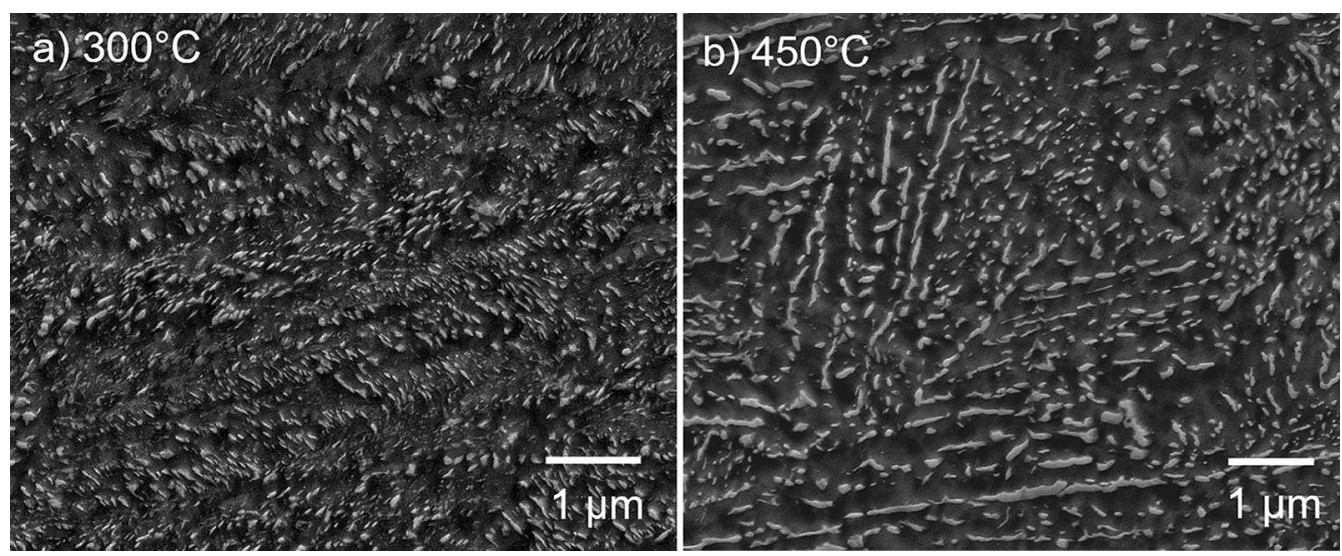

Fig. 6-SEM images of bainite formed at (a) $300^{\circ} \mathrm{C}$, (b) $450^{\circ} \mathrm{C}$ etched with picric acid.
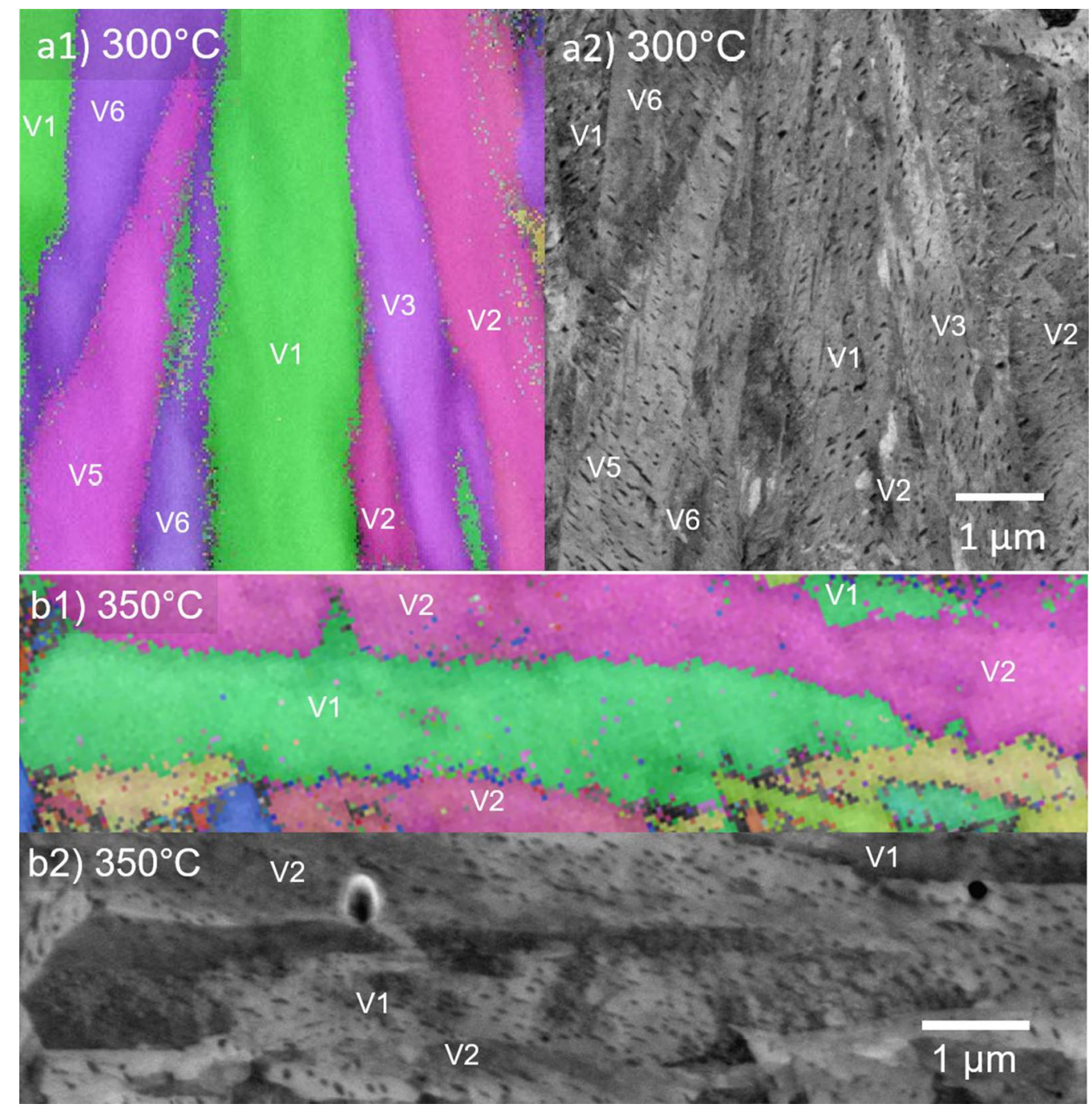

Fig. 7- (a) IPF $(a 1, b 1)$ and ECCI $(a 2, b 2)$ of bainite from (a) $300{ }^{\circ} \mathrm{C}$ and $(b) 350^{\circ} \mathrm{C}$ of the same areas. It can be seen that variant pairs $\mathrm{V} 1-\mathrm{V} 6$ (V2-V3) have cementite at an angle while variant pairs V1-V2 (V5-V6) have cementite roughly oriented in the same direction.

known that different variant pairs accommodate the shape strain differently as presented for lath martensite by Morito et al. ${ }^{[32]}$, Table II. Morito et al also suggested that the lowest transformation strains are obtained when combining all variants and could thus explain why there are alternating variant pairs equivalent to the dominant pair. The influence from carbon on the Ms 


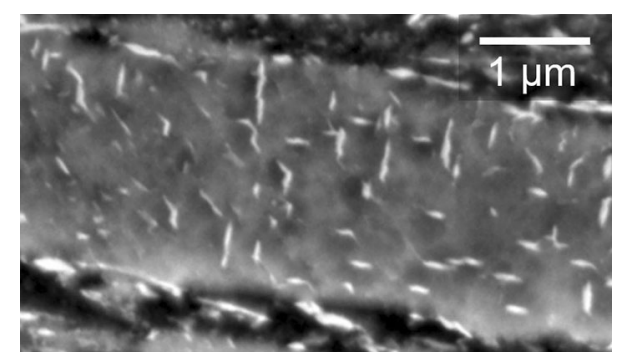

Fig. 8- SEM of martensite tempered at $300{ }^{\circ} \mathrm{C}$ for one hour.

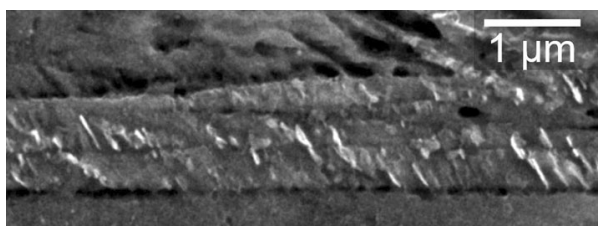

Fig. 9-SEM of bainite after 300 s at $275{ }^{\circ} \mathrm{C}$ showing the initial ferrite plate in the middle covered by cooperatively formed eutectoid of cementite and ferrite.

temperatures and its correlation to the preferred variant pairing was also discussed by Stormvinter et al. ${ }^{[33]}$

In this work the exact reason for the change in variant pairing cannot be concluded but the similarities between bainite and martensite are clear and could be related to the change in conditions for accommodation of strains rather than an effect of the driving force on the nucleation of different variants since an increase in variant selection with decreasing temperature for bainite is not observed in this study.

\section{Cementite Related to the Variant Pairing of Bainitic Ferrite}

For cementite in bainite there is an additional condition for the growth direction compared to martensite, since it is formed together with ferrite in connection with austenite as shown in Figure 9. This differs from martensite where the cementite precipitate within the martensite and thus form without any contact with the austenite. It is clearly seen that the cementite in the martensite have grown in three different directions, see Figure 8, which differs markedly from the cementite in bainite in Figure 9.

It is further observed that cementite within two different variants sharing the same parallel direction with austenite are parallel with each other, e.g., cementite in V1 $\left(\left[\begin{array}{lll}-\mathbf{1} & \mathbf{0} & \mathbf{1}\end{array}\right]_{\gamma} \|\left[\begin{array}{llll}-1 & -1 & 1\end{array}\right]_{\alpha}\right)$ and V2 $\left(\left[\begin{array}{llll}-\mathbf{1} & \mathbf{0} & \mathbf{1}\end{array}\right]_{\gamma} \|\right.$ $\left[\begin{array}{lll}-1 & 1-1\end{array}\right]_{\alpha}$ ), as shown in Figure 7(b). In addition, cementite in variants which do not share the same parallel direction within the same CP-group, are separated with an angular difference of approximately $120^{\circ}$ to each other. This can be seen in Figure 7(a), but it is also evident at lower temperature, see Figure 6(a). These observations are equivalent to all variant pairs corresponding to V1-V6 and V1-V2, Table II. Both these observations are additional indications that bainite forms by an eutectoid transformation together with ferrite from austenite.

\section{CONCLUSION}

1. Three distinct variant pairs are observed in bainite formed at different austempering temperatures, V1-V6 at low temperatures, V1-V2 at intermediate temperature and V1-V4 at high temperature and thus, it is not possible to apply the terminology of upper and lower bainite directly with regard to a specific variant pairing in bainite.

2. For variant pairing V1-V4, there is rather a gradual change in misorientation than sharp boundaries between bainitic ferrite units and it could be questioned if it should be described as a variant pair equivalent to the variant pairs at lower temperature where there are distinct boundaries between the variants.

3. For bainite formed at the lower temperature the variants, V1-V6, form at an angle to each other, while at intermediate temperatures the variants, V1-V2, form more parallel to each other, but in both cases the growth of the variant pairs seems to occur simultaneously.

4. Both changes in variant pairing and morphology of the bainite are gradual with increasing temperature, no sharp transitions are observed.

5. At the lower temperatures, cementite in variants sharing the same parallel close-packed direction with austenite are parallel. This is not observed in bainite formed at higher temperature which further emphasizes the differences between bainite formed at low versus high austempering temperatures.

6. There are similarities in variant pairing in bainite and martensite which can be related to the fact that both transformations are displacive and can be affected by the accommodation of strains.

\section{ACKNOWLEDGMENT}

Open access funding provided by Royal Institute of Technology. Husqvarna AB, Yngströms Stiftelse, Stiftelsen A $\mathrm{H}$ Göransson and the European Union's Horizon 2020 research and innovation program under grant agreement No 686135 are acknowledged for financial support.

\section{OPEN ACCESS}

This article is licensed under a Creative Commons Attribution 4.0 International License, which permits use, sharing, adaptation, distribution and reproduction in any medium or format, as long as you give appropriate credit to the original author(s) and the source, provide a link to the Creative Commons licence, and indicate if changes were made. The images or other third party material in this article are included in the article's Creative Commons licence, unless indicated otherwise in a credit line to the material. If material is 
not included in the article's Creative Commons licence and your intended use is not permitted by statutory regulation or exceeds the permitted use, you will need to obtain permission directly from the copyright holder. To view a copy of this licence, visit http://creat ivecommons.org/licenses/by/4.0/.

\section{REFERENCES}

1. M. Hillert: Jernkontorets Ann., 1957, vol. 141, pp. 757-89.

2. A. Borgenstam, M. Hillert, and J. Ågren: Acta Mater, 2009, vol. 57 , pp. 3242-52.

3. A. Borgenstam, P. Hedstroem, M. Hillert, P. Kolmskog, A. Stormvinter, and J. Aagren: Metall. Mater. Trans. A, 2011, vol. 42A, pp. $1558-74$.

4. P. Kolmskog, PhD thesis, Royal Institute of Technology, SWE, 2013.

5. M. Hillert, L. Höglund, and J. Ågren: Metall. Mater. Trans. A, 2004, vol. 35A, pp. 3693-3700.

6. H.I. Aaronson, W.T. Reynolds, Jr, G.J. Shiflet, and G. Spanos: Metall. Mater. Trans. A, 1990, vol. 21A, pp. 1343-80.

7. L. Fielding: University of Cambridge, UK, 2013.

8. L.C.D. Fielding: Mater. Sci. Technol., 2013, vol. 29, pp. 383-99.

9. F.G. Caballero, C. Garcia-Mateo, M.J. Santofimia, M.K. Miller, and C. Garcia de Andres: Acta Mater., 2008, vol. 57, pp. 8-17.

10. F.G. Caballero, M.K. Miller, and C. Garcia-Mateo: Acta Mater., 2010, vol. 58, pp. 2338-43.

11. H.K.D.H. Bhadeshia and D.V. Edmonds: Acta Metall., 1980, vol. 28, pp. 1265-73.

12. F.G. Caballero, M.K. Miller, and C. Garcia-Mateo: Mater. Chem. Phys., 2014, vol. 146, pp. 50-57.

13. J. Yin, M. Hillert, and A. Borgenstam: Metall. Mater. Trans. A, 2017, vol. 48A, pp. 1444-58.

14. J. Yin, M. Hillert, and A. Borgenstam: Metall. Mater. Trans. A, 2017, vol. 48A, pp. 5294-5303.

15. J. Yin, M. Hillert, and A. Borgenstam: Metall. Mater. Trans. A, 2017, vol. 48A, pp. 1425-43.

16. M. Hillert: Interscience, $N Y, 1962,197-237$.

17. H. I. Aaronson, The Proeutectoid Ferrite and the Proeutectoid Cementite Reaction, 1962, 387.

18. J. Yin, M. Hillert, and A. Borgenstam: Metall. Mater. Trans. A, 2017, vol. 48A, pp. 4006-24.

19. R. Mehl: ASM, Metals Park, $O H, 1939,1$.

20. Y. Ohmori, H. Ohtani, and T. Kunitake: Trans. Iron Steel Inst. Jpn., 1971, vol. 11, pp. 250-59.

21. M. Takahashi and H. Bhadeshia: Mater. Sci. Technol., 1990, vol. 6 , pp. 592-603.

22. G. Spanos, H. Fang, and H. Aaronson: Metall. Mater. Trans. A, 1990, vol. 21A, pp. 1381-90.

23. S. Matas and R. Hehemann: Trans. Metall. Soc. AIME, 1961, vol. 221, pp. 179-85.
24. T. Furuhara, in Phase Transformations in Steels, eds. E. Pereloma and D. V. Edmonds, Woodhead Publishing, 2012, pp. 417-35.

25. F. B. Pickering, Transformation and Hardenability in Steels, Climax Molybdenum Company 1967.

26. G. Kurdjumow and G. Sachs: Z. Phys., 1930, vol. 64, pp. 325-43.

27. A.B. Greninger and AR. Troiano: JOM, 1949, vol. 1, pp. 590-98.

28. Z. Nishiyama: Sci. Rep. Tohoku Univ., 1934, vol. 23, p. 637.

29. G. Wassermann, Über den Mechanismus der $\alpha-\gamma$ Umwandlung des Eisens, Verlag Stahleisen, 1935.

30. G.R. Purdy and M. Hillert: Acta Metall., 1984, vol. 32, pp. 823-28.

31. T. Moritani, N. Miyajima, T. Furuhara, and T. Maki: Scr. Mater., 2002, vol. 47, pp. 193-99.

32. S. Morito, H. Tanaka, and R. Konishi: T. Furuhara and MakiActa Mater, 2003, vol. 51, pp. 1789-99.

33. A. Stormvinter, G. Miyamoto, T. Furuhara, P. Hedström, and A. Borgenstam: Acta Mater, 2012, vol. 60, pp. 7265-74.

34. T. Kaneshita, G. Miyamoto, and T. Furuhara: Acta Mater., 2017, vol. 127 , pp. $368-78$.

35. T. Furuhara, H. Kawata, S. Morito and T. Maki: Mater. Sci. Eng., A, 2006, 431, 228-36.

36. H. Kawata, K. Sakamoto, T. Moritani, S. Morito, T. Furuhara, and T. Maki: Mater. Sci. Eng. A, 2006, vol. 438A, pp. 140-44

37. A. Ståhlkratnz, P. Hedström, N. Sarius, H.-A. Sundberg, S. Kahl, M. Thuvander, and A. Borgenstam: Metall. Mater. Trans. A, 2020 , vol. 51A, pp. $6470-81$.

38. R. Hielscher and H. Schaeben: J. Appl. Crystallogr., 2008, vol. 41, pp. 1024-37.

39. F. Bachmann, R. Hielscher and H. Schaeben, Solid State Phenom., 2010, pp. 63-68.

40. T. Nyyssönen, M. Isakov, P. Peura, and V.-T. Kuokkala: Metall. Mater. Trans. A, 2016, vol. 47A, pp. 2587-90.

41. S. M. Van Dongen, PhD thesis, Utrecht University, NL, 2000

42. E. Gomes and L. Kestens, in IOP conference series: materials science and engineering, IOP Publishing, 2015, p. 012059.

43. T. Nyyssönen, $\mathrm{PhD}$ thesis, Tampere University of Technology, FI, 2017.

44. G. Miyamoto, N. Iwata, N. Takayama, and T. Furuhara: Acta Mater., 2010, vol. 58, pp. 6393-6403.

45. G. Miyamoto, N. Iwata, N. Takayama, and T. Furuhara: Acta Mater., 2012, vol. 60, pp. 1139-48.

46. N. Takayama, G. Miyamoto, and T. Furuhara: Acta Mater., 2012, vol. 60 , pp. 2387-96.

47. S. Morito, X. Huang, T. Furuhara, T. Maki, and N. Hansen: Acta Mater., 2006, vol. 54, pp. 5323-31.

48. S. Morito, A. Pham, T. Hayashi, and T. Ohba: Mater. Today, 2015, vol. 2, pp. S913-16.

49. G. Srinivasan and C. Wayman: Acta Metall., 1968, vol. 16, pp. 621-36.

Publisher's Note Springer Nature remains neutral with regard to jurisdictional claims in published maps and institutional affiliations. 